\title{
Marsh vulnerability to sea-level rise
}

To the Editor - We question the conclusion of Kirwan et al. ${ }^{1}$ suggesting marsh vulnerability to sea-level rise (SLR) is overstated. Their thesis is based upon the inclusion of short duration (years) sediment elevation and marker horizon (SET-MH) data that exaggerate marsh resilience relative to estimates incorporating the historical (decades to centuries), cumulative effects of subsurface processes. Moreover, their dynamic modelling yields results inconsistent with the Holocene stratigraphic record.

Rates of coastal marsh sedimentation estimated using SET-MH data typically yield higher values than those based upon radiometric geochronologies $\left({ }^{137} \mathrm{Cs},{ }^{210} \mathrm{~Pb}\right.$ and $\left.{ }^{14} \mathrm{C}\right)$, which decrease with increasing age of sediment (Supplementary Table 1). Such differences are generally attributed to mechanical compaction and decomposition ${ }^{2,3}$. The authors exclude SET-MH measurements lasting less than three years, but the balance of remaining data is limited ${ }^{4}$ and generally represents less than a decade of observations. Hence, it is highly unlikely the cumulative effects of subsurface processes were fully integrated into the stratigraphic sequence. By including SET-MH measurements, Kirwan et al. overestimate marsh resilience to SLR. Radiometric geochronologies should be considered a more viable means of forecasting resilience as they yield estimates of marsh sedimentation representing time-averaged processes operating over decades to centuries - the same interval over which predictions of climate change and SLR are typically discussed.
The authors argue forecasts using historical data overestimate vulnerability because ecogeomorphic feedbacks, which could more than double sediment accretion rates during the transition from high to low marsh, are not considered. A more meaningful assessment, they suggest, should focus solely upon low marsh data. This is easily disputed given the worldwide presence of extant low marsh habitat. According to Kirwan et al., the distribution of low marsh habitat along modern coastlines should be minimal because the average rate of global eustatic SLR over the past 4,000 years $(<0.5 \mathrm{~mm}$ per year) was much slower than the mean rate of low marsh accretion (6.9 mm per year) they present. Based upon our observations, coastal sedimentation and the resulting historical record of accretion represents the sum of all environmental processes operating within the marsh and indeed does include relevant ecogeomorphic feedbacks.

Finally, Kirwan et al. present dynamic models suggesting marshes can survive rates of SLR of 10-50 mm per year. The stratigraphic record in no way supports this conclusion. Mid-Holocene coastal sedimentary environments were submerged when rates of SLR were much less than $10 \mathrm{~mm}$ per year (refs 5-7). The presence of basal marsh and mangrove peats conformably overlain by back-barrier lagoon or nearshore sediments and extending well onto the continental shelf attest to the effects of this marine transgression ${ }^{7-9}$.

\footnotetext{
References

1. Kirwan, M. L., Temmerman, S., Skeehan, E. E., Guntenspergen, G. R. \& Fagherazzi, S. Nat. Clim. Change 6, 253-260 (2016).
}

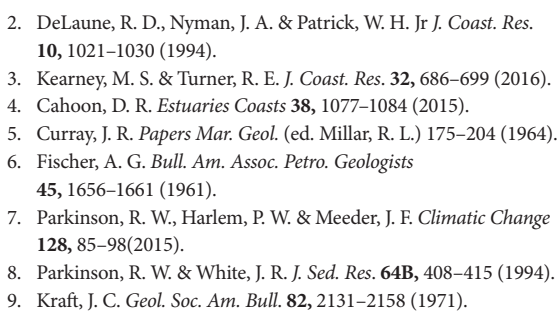

2. DeLaune, R. D., Nyman, J. A. \& Patrick, W. H. Jr J. Coast. Res. 10, 1021-1030 (1994).

3. Kearney, M. S. \& Turner, R. E. J. Coast. Res. 32, 686-699 (2016).

4. Cahoon, D. R. Estuaries Coasts 38, 1077-1084 (2015).

5. Curray, J. R. Papers Mar. Geol. (ed. Millar, R. L.) 175-204 (1964).

6. Fischer, A. G. Bull. Am. Assoc. Petro. Geologists 45, 1656-1661 (1961)

7. Parkinson, R. W., Harlem, P. W. \& Meeder, J. F. Climatic Change 128, 85-98(2015).

8. Parkinson, R. W. \& White, J. R. J. Sed. Res. 64B, 408-415 (1994)

9. Kraft, J. C. Geol. Soc. Am. Bull. 82, 2131-2158 (1971).

Randall W. Parkinson ${ }^{1 \star}$, Christopher Craft ${ }^{2}$, Ronald D. DeLaune ${ }^{3}$, Joseph F. Donoghue ${ }^{4}$, Michael Kearney ${ }^{5}$, John F. Meeder ${ }^{6}$, James Morris ${ }^{7}$ and R. Eugene Turner ${ }^{8}$ ${ }^{1} S e a$ Level Solutions Center, Florida International University, Miami, FL 33199, USA. ${ }^{2} \mathrm{~S}$ chool of Public and Environmental Affairs, Indiana University, Bloomington, IN 47405, USA. ${ }^{3}$ College of the Coast and Environment, Department of Oceanography and Coastal Sciences, Louisiana State University, Baton Rouge, LA 70803, USA. ${ }^{4}$ National Center for Integrated Coastal Research, University of Central Florida, Orlando, FL 32816-2385, USA. ${ }^{5}$ Department of Environmental Science and Technology, University of Maryland, College Park, MD 20742, USA. ${ }^{6}$ Southeast Environmental Research Center, Florida International University, Miami, FL 33199, USA ${ }^{7}$ Department of Biological Sciences, University of South Carolina, Columbia, SC 29208, USA. ${ }^{8}$ Department of Oceanography and Coastal Sciences, Louisiana State University, Baton Rouge, LA 70803, USA.

*e-mail: rwparkins@fiu.edu

Additional information

Supplementary information is available in the online version of the paper.

\section{Reply to 'Marsh vulnerability to sea-level rise'}

Kirwan et al. reply - Parkinson et al. argue that our meta-analysis of marsh accretion rates is based on short-term ( $<10$ year) measurements of elevation change that exaggerate marsh stability relative to longer-term (10-1,000 year) estimates of accretion ${ }^{1,2}$. In reality, we included both long-term $(n=93)$ and short-term $(n=47)$ measurements. We used short-term, SET marker horizon measurements because they more fully account for shallow subsidence ${ }^{3,4}$, and do not integrate over long-term periods of relatively slow sea-level rise (SLR). For example, it makes little sense to use radiocarbon-derived, millennial timescale accretion rates that reflect conditions of very slow SLR (as in Supplementary Table 1 in Parkinson et al.) to assess vulnerability of marshes to modern, rapid SLR.

In any case, the conclusions of our meta-analysis do not change even if we accept the premise of Parkinson et al. that marsh vulnerability should only be assessed with long-term, core-derived accretion data, or if we use their dataset instead of ours. Re-analysis of our dataset excluding all short-term measures of marsh accretion and elevation change confirm our original conclusions: i) marsh accretion rates are higher in frequently flooded, low-elevation marshes ( $6.5 \mathrm{~mm}$ year $\left.{ }^{-1}\right)$ than infrequently flooded, high-elevation marshes (1.1 $\mathrm{mm}$ year $\left.{ }^{-1}\right)$, and ii), that a very small percentage of low-elevation marshes ( 2 of 28 ) are accreting slower than the historical rate of SLR. Interestingly, Parkinson et al.'s own accretion data illustrate a similar tendency for marshes 